\title{
Low temperature heat capacity measurements on $\mathrm{HoBa}_{2} \mathrm{Cu}_{3} \mathrm{O}_{7-\delta}$
}

\author{
B K BASU, S M PATTALWAR, R N DIXIT and S Y SHETE \\ Tata Institute of Fundamental Research, Homi Bhabha Road, Bombay 400005, India
}

\begin{abstract}
Specific heats were measured on two samples of $\mathrm{HoBa}_{2} \mathrm{Cu}_{3} \mathrm{O}_{7-\delta}$ in the temperature range $1.7 \mathrm{~K}$ to $10 \mathrm{~K}$. In addition to the known Schottky behaviour, a peak in the specific heat curve was observed near $7.9 \mathrm{~K}$ in both the samples. This peak is probably due to impurity contribution and the specific heat measurements were undertaken in holmium oxide $\left(\mathrm{Ho}_{2} \mathrm{O}_{3}\right)$, which was the suspected impurity. However, no peak was observed in the specific heat curve of holmium oxide.
\end{abstract}

Keywords. Specific heat; high $T_{c}$ superconductors; low temperature; $\mathrm{HoBa}_{2} \mathrm{Cu}_{3} \mathrm{O}_{7-\delta}$.

\section{Introduction}

In compounds $\mathrm{RBa}_{2} \mathrm{Cu}_{3} \mathrm{O}_{7}$ ( $\mathrm{R}$ stands for rare earth ion except $\mathrm{Ce}, \mathrm{Pr}, \mathrm{Pm}$ and $\mathrm{Tb}$ ), heat capacity measurements at low temperatures show sample-to-sample variations. The reason for this behaviour is not known. It is necessary to check if the amount of superconductivity in the materials has any effect on the low-temperature behaviour. Earlier Basu et al (1989) have carried out high precision heat capacity measurements on $\mathrm{HoBa}_{2} \mathrm{Cu}_{3} \mathrm{O}_{7-\delta}$ near the superconducting transition temperature. In this report we present low temperature heat capacity measurement in two samples of $\mathrm{HoBa}_{2} \mathrm{Cu}_{3} \mathrm{O}_{7-\delta}$ with different superconducting fractions.

\section{Sample preparation}

The preparation and processing of the samples were reported earlier (Basu et al 1988, 1989). Sample 1 had a $T_{c}$ of $85 \mathrm{~K}$ and the specific heat jump $\Delta C_{p} / T_{c} \simeq 8 \mathrm{~mJ} / \mathrm{mol} \mathrm{K}^{2}$ and sample 2 had a $T_{c}$ of $90 \mathrm{~K}$ and the jump $\Delta C_{p} / T_{c} \simeq 22 \mathrm{~mJ} / \mathrm{mol} \mathrm{K}^{2}$. The high temperature and low temperature measurements were done in these samples within a period of one month.

\section{Measurements and discussion}

The heat capacity was measured by the usual heat pulse technique. The accuracy of the measurement was about $3 \%$. Figure 1 shows the results of low-temperature heat capacity measurements. In the holmium-based samples the low temperature heat capacity measurements were done by several experiments (Nakazawa et al 1987; Ferreira et al 1988; van der Meulen et al 1988), and our results are quite comparable with their results. The heat capacity in this compound is rather large at low temperatures and is attributed to Schottky anomaly (Ferreira et al 1988) arising from the interaction of the RE-ions with the crystalline electric field. Their assignment of 


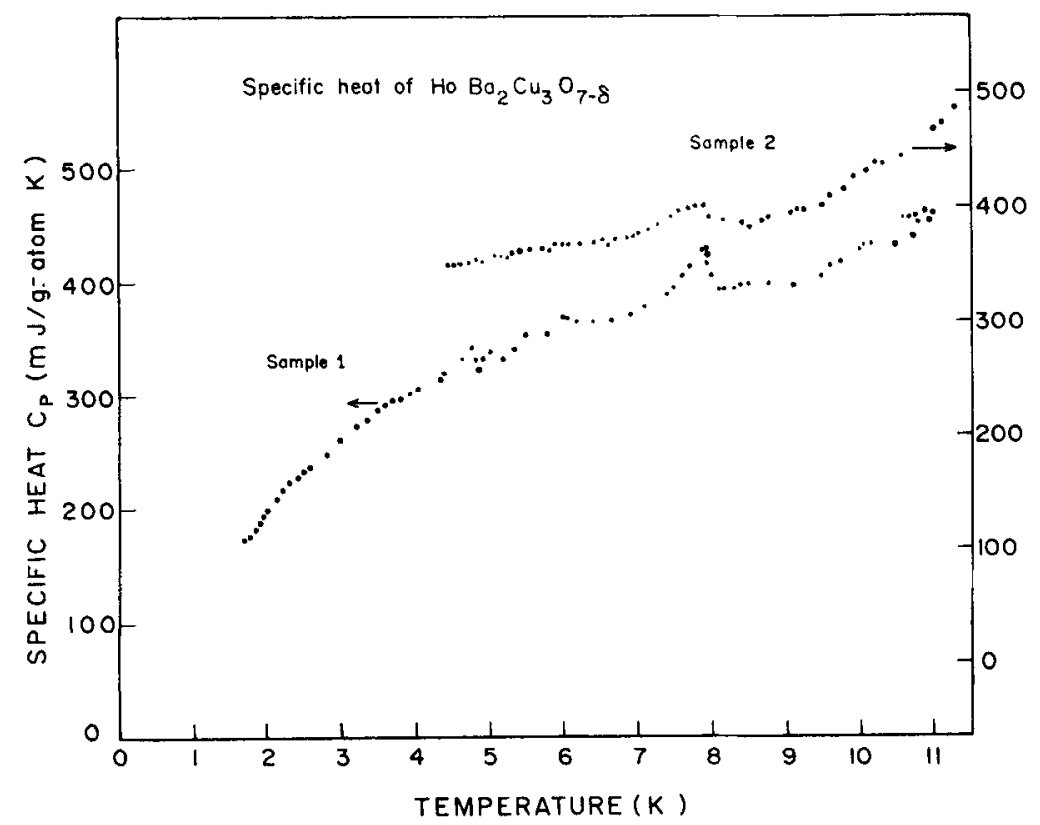

Figure 1. Specific heat of superconducting $\mathrm{HoBa}{ }_{2} \mathrm{Cu}_{3} \mathrm{O}_{7-\delta}$ vs temperature.

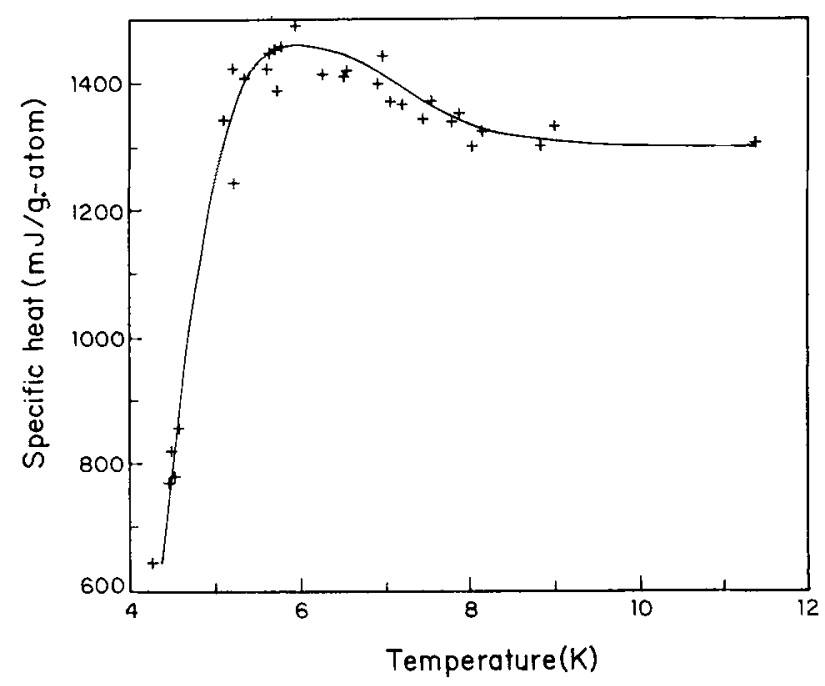

Figure 2. Specific heat of $\mathrm{Ho}_{2} \mathrm{O}_{3}$ vs temperature.

Schottky levels follows the experimental curve quite closely. The heat capacity curves, as reported by different authors, in general, agree. We, therefore, conclude that it is not possible to detect the effect of the amount of superconductivity in $\mathrm{HoBa}_{2} \mathrm{Cu}_{3} \mathrm{O}_{7-\delta}$ in the low-temperature behaviour.

One of the features seen in the low temperature heat capacity curves of $\mathrm{HoBa}_{2} \mathrm{Cu}_{3} \mathrm{O}_{7-\delta}$ (figure 1) is that there is a peak near $7.9 \mathrm{~K}$ in our measurements 
although others did not report any peak at this temperature. We, therefore, felt that this peak may be due to some excess of one of the component compounds i.e. $\mathrm{CuO}_{2}, \mathrm{Ba}_{2} \mathrm{CO}_{3}$ and $\mathrm{Ho}_{2} \mathrm{O}_{3}$. Eckert et al (1988) measured the low-temperature specific heats of $\mathrm{CuO}_{2}$ and $\mathrm{Ba}_{2} \mathrm{CO}_{3}$ and no peak was observed at $7.9 \mathrm{~K}$. We have, therefore, measured the low-temperature heat capacity of $\mathrm{Ho}_{2} \mathrm{O}_{3}$ and this is shown in figure 2. $\mathrm{Ho}_{2} \mathrm{O}_{3}$ is a good insulator and the pulse method of heat capacity measurement presented some problems. The accuracy of this measurement, we find, is not better than $5 \%$. However, we do not see any peak near $7.9 \mathrm{~K}$. If the excess $\mathrm{Ho}_{2} \mathrm{O}_{3}$ is responsible for the unusual peak in figure 1, it should show a large peak at $7.9 \mathrm{~K}$ in the specific heat curve of $\mathrm{Ho}_{2} \mathrm{O}_{3}$ (figure 2). However, the peak is absent.

\section{Conclusion}

We conclude that the amount of superconductivity in $\mathrm{HoBa}_{2} \mathrm{Cu}_{3} \mathrm{O}_{7-\delta}$ is not detected in the low temperature behaviour. A peak near about $7.9 \mathrm{~K}$ has been observed in our measurement. The starting compounds i.e. $\mathrm{Ba}_{2} \mathrm{CO}_{3}, \mathrm{Ho}_{2} \mathrm{O}_{3}$ and $\mathrm{CuO}_{2}$, for preparing $\mathrm{HoBCO}$ are not responsible for this peak. Further work is in progress.

\section{References}

Basu B K, Pattalwar S M, Dixit R N, Shete S Y, Rajarajan A K, Gupta L C and Vijayaraghavan R 1988 Pramana-J. Phys. 30 L367-L370

Basu B K, Pattalwar S M, Dixit R N, Shete S Y, Chandra G, Sannabhadti R S and Nigam A K 1989 Physica C159 379

Eckert D, Junod A, Bezinge A, Graf T and Muller J 1988 J. Low Temp. Phys. 73241

Ferreira J M, Lee B W, Dalichaouch Y, Torikachvili M S, Yang K N and Maple M B 1988 Phys. Rev. B37 1580

Meulen Van Der, Franse J J M, Tarnaski Z, Kadowaki K, Klaasse I C P and Menovsky A A 1988 Physica C152 65

Nakazawa Y, Ishikava M and Takabatake T 1987 Physica B148 404 